\title{
Study on the Addition of Solar Generating and Energy Storage Units to a Power Distribution System
}

\author{
T. Costa, D. Narvaez, K. Melo, M. Villalva
}

\begin{abstract}
Installation of micro-generators based on renewable energy in power distribution system has increased in recent years, with the main renewable sources being solar and wind. Due to the intermittent nature of renewable energy sources, such microgenerators produce time-varying energy which does not correspond at certain times of the day to the peak energy consumption of end users. For this reason, the use of energy storage units next to the grid contributes to the proper leveling of the buses' voltage level according to Brazilian energy quality standards. In this work, the effect of the addition of a photovoltaic solar generator and a store of energy in the busbar voltages of an electric system is analyzed. The consumption profile is defined as the average hourly use of appliances in a common residence, and the generation profile is defined as a function of the solar irradiation available in a locality. The power summation method is validated with analytical calculation and is used to calculate the modules and angles of the voltages in the buses of an electrical system based on the IEEE standard, at each hour of the day and with defined load and generation profiles. The results show that bus 5 presents the worst voltage level at the power consumption peaks and stabilizes at the appropriate range with the inclusion of the energy storage during the night time period. Solar generator maintains improvement of the voltage level during the period when it receives solar irradiation, having peaks of production during the $12 \mathrm{pm}$ (without exceeding the appropriate maximum levels of tension).
\end{abstract}

Keywords-Energy storage, power distribution system, solar generator, voltage level.

\section{INTRODUCTION}

$\mathrm{S}$ GNIFICANT transformations in electricity distribution systems have been occurring in the last decades, mainly in their structure, design, and operation. Also, awareness of environmental issues, the development of new technologies and incentives advances provided by legislation for undertakings with alternative energy sources contribute to the insertion of generation in the consumption units. From this, studies of power distribution grids play a fundamental role in ensuring the quality of the energy supply to consumers, but for this, it must have tools and models that can simulate and provide results of the behavior of the grid in permanent and transient regime [1].

In a large part of the literature, authors [2]-[8] present changes in the power grids and power flow theories traditional concepts. The conventional radial distribution system is configured to have only one source of generation with the oneway power flow starting its generation path until the final

T. Costa, D. Narváez, K. Melo, and M. Villalva are with the School of Electrical and Computer Engineering, University of Campinas (UNICAMP), Brazil (e-mail: tati_costa@rocketmail.com, dante.innar@gmail.com, karen.bmelo@gmail.com, villalva@g.unicamp.br). consumption, as in Fig. 1. But from the inclusion of generators in the distribution grid this flow turns into two-way, becoming a system of multiple sources, as in Fig. 2.

Current studies aim at identifying the consequences of the connection of electricity generation sources on the consumer side or the distribution network, and the impact on system operations, reliability, power quality, and control.

The penetration of generators altered the functioning of distribution networks that until then were passive. From this, new perspectives of grid analysis are necessary, considering it not only as a load but also as a source of energy.

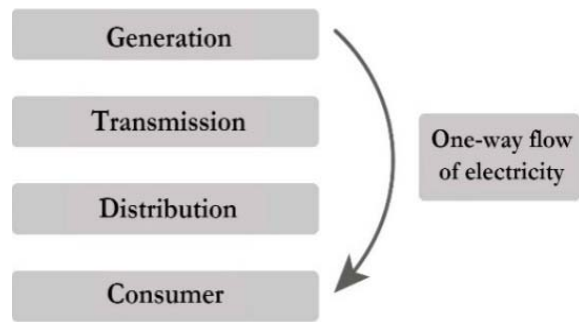

Fig. 1 Traditional power system with one-way flow electricity

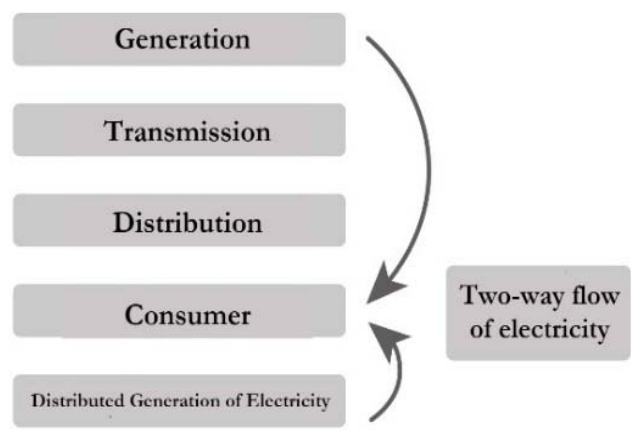

Fig. 2 Power system with two-way flow electricity

Reverse energy flow results in overloading the distribution feeders and in excessive power losses. Also, the capacitor banks and the voltage regulators that are used to increase the voltage slightly can now further increase the voltage, above acceptable limits in national legislation.

TABLE I

VOLTAGE LEVELS ACCORDING TO NATIONAL STANDARD

\begin{tabular}{cc}
\hline $\begin{array}{c}\text { Service } \\
\text { voltage }\end{array}$ & $\begin{array}{c}\text { Range of Reading Voltage (TL) in } \\
\text { Relation to Rated Voltage (TN) }\end{array}$ \\
\hline Suitable & $0.92 \mathrm{TN} \leq \mathrm{TL} \leq 1.05 \mathrm{TN}$ \\
& $0.87 \mathrm{TN} \leq \mathrm{TL}<0.92 \mathrm{TN}$ or \\
Precarious & $1.05 \mathrm{TN}<\mathrm{TL} \leq 1.06 \mathrm{TN}$ \\
Critical & $\mathrm{TL}<0.87 \mathrm{TN}$ or $\mathrm{TL}>1.06 \mathrm{TN}$ \\
\hline
\end{tabular}


The voltage of the feeder (nominal) shall be taken as a reference to analyze the voltage values after insertion of the photovoltaic systems. The reference voltage is compared with the reading voltage (different voltage values are set for each voltage range), in which it must be classified into three categories: adequate, precarious, or critical (Table I) [9].

The network system without any insertion of photovoltaic systems can present voltage levels that fit between the precarious and critical levels. Even when properly sized, the system connected to the grid is a source that carries with it the intermittent generation of energy that is a concern to the distribution system that requires stable and reliable energy production all the time. In this context, one finds the importance of the energy storage system as a part of the solution to stabilize the effects of solar flashing and as an energy damper for a photovoltaic system connected to the grid. Moreover, a battery's energy storage system can potentially address this flicker per hour by storing energy and injecting power into the network when needed. The integration of a large number of lithium-ion batteries with the photovoltaic system in the large-scale grid will control the energy flow of the photovoltaic system and will ensure the production of stable energy as needed.

For the analysis of the effects of the installation of renewable-energy-based generators and energy storage systems in the distribution grid, computer programs are used both in steady-state (power flow methods) and in transient (circuit simulation).

The primary objective of this work is to simulate the permanent regime using the power summation method using MATLAB to understand its use in systems with alternative generators and energy storage. First, the problem is solved analytically. Then, the simulations results will be presented from data taken from part of a radial grid of 30 busbars for tests [10]. Finally, the conclusions of the case studies are presented.

\section{II.POWER SUMMATION METHOD}

The power summation method is an iterative procedure for solving the power flow problem in an electric system. This method allows to obtain a fast solution for the bus's voltages (subsystem 1) in a mainly radial distribution grid, making possible the calculation of the powers that are injected in the grid buses (subsystem 2) [11], [12].

The Power Summation Method is based on two scanning processes of the branches and buses of the tested grid, which are repeated until some stop criterion is reached:

Inverse scan: resides in the cumulative process of power, from the terminal nodes to the root node.

Direct scan: consists of correcting (re-estimating) the state of the bar voltages (modulus and angle) towards the terminal nodes of the grid, from the known voltage and angle for the root node.

\section{A. Subsystem 1}

The iterative solution process of Subsystem 1 based on the Power Summation Method can be implemented primarily in a sequence of 5 steps, described below:

$1^{\mathrm{o}}$ stage (iteration 0 ): initially, adopt any state (module and angle) for the grid's bars, except for the (known) source node. Usually, it assumes the so-called flat-start $\left(1\left\llcorner 0^{\circ}\right)\right.$.

$2^{\circ}$ stage (loss calculation): for any iteration and based on the state of the bar voltages obtained in the previous iteration, calculate the active and reactive losses in all branches of the grid. Then, be the generic branch $k-$ mof admittance series $\hat{y}_{k m}=g_{k m}+j b_{k m}$ given in Fig. 3, where it is assumed that the complex voltages $\hat{E}_{k}=V_{k}\left\llcorner\theta_{k}\right.$ in the busk e $\widehat{E}_{m}=V_{m}\left\llcorner\theta_{m}\right.$ in the bus $m$.

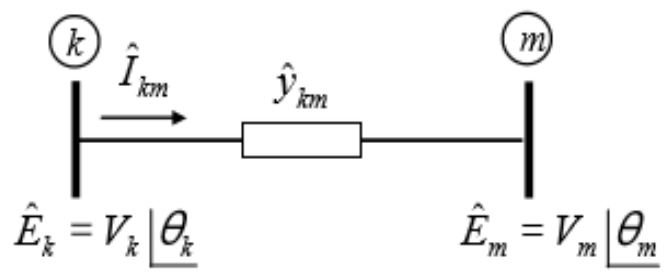

Fig. 3 Generic branch $k-m$ for the calculation of losses

$3^{\circ}$ stage (reverse scan): accumulate active and reactive powers in each bus, starting from the terminal nodes towards the root node, using the last estimate of the state of the nodal voltages. For a generic branch $k-m$, where bus $m$ is located farther from the source bar (S / E) than the busk, this step then consists of, for the (farthest) bus, adding all the accumulated potencies of the buses and losses of the branches downstream of the bar $m$ previously calculated.

The active $P_{m}^{a c}$ and reactive power $Q_{m}^{a c}$ accumulated in the bus $m$ are determined by:

$$
\begin{gathered}
P_{m}^{a c}=P_{m}^{l i q}+\sum_{i \in \Omega_{m}}\left(P_{i}^{a c}-P_{m i}^{\text {perdas }}\right) \\
Q_{m}^{a c}=Q_{m}^{l i q}+Q_{m}^{s h} \sum_{i \in \Omega_{m}}\left(Q_{i}^{a c}-Q_{m i}^{\text {perdas }}\right)
\end{gathered}
$$

in which: $P_{m}^{l i q}=P_{m}^{G}-P_{m}^{C}$ : liquid injection (generation - load) of active power in the $\mathrm{m}$ bar, such that $P_{m}^{G}$ is the power generatedand $P_{m}^{C}$ is the power consumed in the rod. It is assumed that if the numerical value of the liquid injection is positive, it is associated with a predominance of active power generation in the bar and, if negative, a dominance of active load consumed in the bus. $Q_{m}^{l i q}=Q_{m}^{G}-Q_{m}^{C}$ : known liquid injection of reactive power in $m$ bus, such $Q_{m}^{G}$ is generated power and $P_{m}^{C}$ éis the power consumed in the bar. Similarly, if the numerical value of the liquid injection is positive, it is associated with a predominance of reactive power generation in the bar and, if negative, a dominance of reactive load consumed in the bus. $\Omega_{m}$ : set of all the i bars connected downstream of the $m$ bus, i.e., all the bars attached to the $m$ bar except for the $k$ bus. $P_{i}^{a c}$ : active power previously accumulated on the bus $i \in \Omega_{m} . Q_{i}^{a c}$ : reactive power previously accumulated in each bus $i \epsilon \Omega_{m} . P_{m i}^{\text {perdas }}$ : active loss in the branches $m-i, i \in \Omega_{m}$, where the negative signal comes from the fact that the active losses represent loads for the system and, therefore, represent injections of power coming out of the 
bus. $Q_{m i}^{\text {perdas }}$ : reactive loss in the branches $m-i, i \in \Omega_{m}$ where, similarly, the negative signal arises from the fact that the reactive losses represent charges to the system and, therefore, leaving the bus. $Q_{m}^{s h}=V_{m}^{2}-b_{m}^{s h}$ : reactive power shunt injected into them bus. For a capacitor bank, this injection is positive $\left(b_{m}^{s h}>0\right)$ and for a reactors bank, the value is negative $\left(b_{m}^{s h}<0\right)$.

$4^{\mathrm{o}}$ stage (direct scan): from the state of the root node (known) and the branches connected to the root node and toward the terminal nodes, recalculate the complex nodal voltages in each bus.

Then, a generic branch $k-m$ shown in Fig. 4, where $k$ bar is closer to the root node $(\mathrm{S} / \mathrm{E})$ than $m$, the following data are assumed or estimated:

- $\quad \hat{y}_{k m}=g_{k m}+j b_{k m}=y_{k m}\left\llcorner\varphi_{k m}\right.$ : branch admittance $k-m$, where: $y_{k m}=\sqrt{g_{k m}^{2}+b_{k m}^{2}}$ and $\varphi_{k m}=\operatorname{acrtg}\left(b_{k m} / g_{k m}\right)$;

- $\quad \hat{E}_{k m}=V_{k}\left\llcorner\theta_{k}\right.$ : complex voltage on $k$ bus previously recalculated, or know in case of $\mathrm{S} / \mathrm{E}$;

- $\quad S_{m}^{a c}=P_{m}^{a c}+j Q_{m}^{a c}$ : complex apparent power accumulated in $m$ bus, in stage 3 .

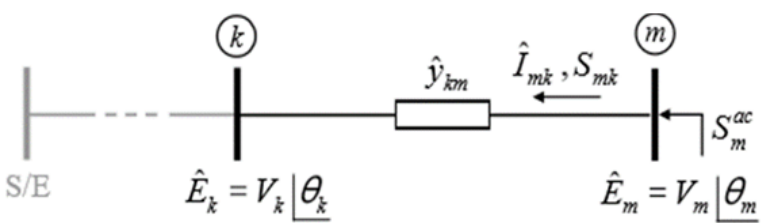

Fig. 4 Generic branch $k-m$ for exemplification of the direct scan

$5^{\circ}$ stage (convergence test): verify convergence by a stop criterion, for example, the module of the most significant difference (error) of nodal voltages between two consecutive iterations $i$ and $-i-1$ :

$$
\max _{k \in \Omega_{N=1}} \xi_{k}=\max _{k \in \Omega_{N=1}}\left|V_{k}^{(i)}-V_{k}^{(i-1)}\right| \leq \varepsilon
$$

where $\xi$ is the bar voltage error, $\Omega_{N=1}$ is the set of grid bars except the root node (bus $V \theta$ ), and $\varepsilon$ is the pre-set tolerance value (for example, $=10^{-4}$ ). At this point, it is assumed that, if convergence is not achieved, it is returned to Stage 2, and if it is reached, the process is finished by saving the last state of busbar voltages obtained and proceeding with the calculations of Subsystem 2.

\section{B. Subsystem 2 - Calculation of Other Results}

This step of calculation consists in obtaining too many unknowns of interest, such as active and reactive flows and losses of branches, and liquid injection of active and reactive powers in the root node. A generic branch k-m of a network under study, is shown in Fig. 5 (a).

Based on Fig. 5 (b), which shows a scheme for obtaining power injections in the source bar (substation), designated here as number 1, it can be seen that the liquid injections of active power $P_{1}^{l i q}$ and reactive $Q_{1}^{l i q}$ correspond to the sum of the flows in the connected branches directly downstream of bus 1. Defining $\Omega_{1}$ the set of all the bars connected downstream of bar 1, then the liquid injections of active and reactive powers in the source bar will be determined by:

$$
\begin{aligned}
& P_{1}^{l i q}=V_{1}^{2} \sum_{m \epsilon \Omega_{1}} g_{1 m}-V_{1} \sum_{m \epsilon \Omega_{1}} V_{m}\left(g_{1 m} \cos \theta_{1 m}+b_{1 m} \operatorname{sen} \theta_{1 m}\right) \\
& Q_{1}^{l i q}=-V_{1}^{2} \sum_{m \epsilon \Omega_{1}} b_{1 m}-V_{1} \sum_{m \epsilon \Omega_{1}} V_{m}\left(g_{1 m} \operatorname{sen} \theta_{1 m}-b_{1 m} \cos \theta_{1 m}\right)
\end{aligned}
$$

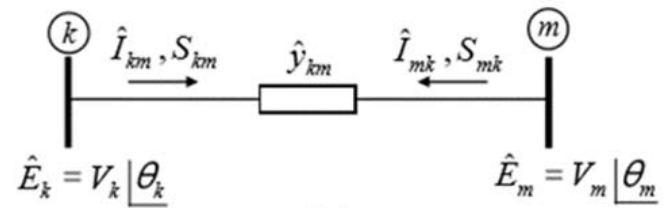

(a)

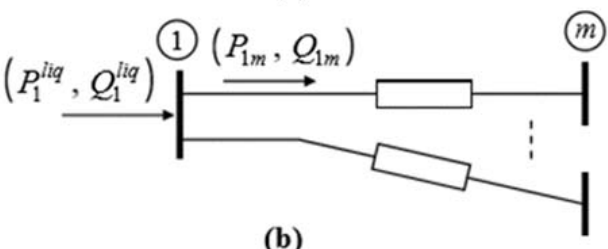

(b)

Fig. 5 (a) generic branch $k-m$ for the calculation of power flows; (b) grid scheme for the computation of the liquid injection of complex apparent power at the substation (bus 1)

\section{Analytical CAlculation}

The case study is given by the two-busbar electrical system shown in Fig. 6. The voltage and power bases are $\mathrm{V}_{\text {base }}=13.8$ $\mathrm{kV}$ and $\mathrm{S}_{\mathrm{base}}=1 \mathrm{MVA}$, respectively, the impedance of line1-2 is $\mathbf{Z}_{\mathbf{1 2}}=2+\mathrm{j} 4 \Omega$, the load power in bus 2 is $\mathbf{S}_{\mathrm{C}}=\mathrm{P}_{\mathrm{C}}+\mathrm{j} \mathrm{Q}_{\mathrm{C}}=1,5+\mathrm{j} 0.8$ p.u. and the generating power at bar 2 is $\mathbf{S}_{\mathrm{G}}=\mathrm{P}_{\mathrm{G}}+\mathrm{jQ}_{\mathrm{G}}=0,5+\mathrm{j} 0.1$ p.u..

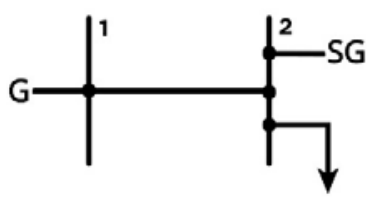

Fig. 6 Two bus system with renewable generator SG

As an example, the voltages in the buses and the power flow according to analytical and iterative (computational) methods will be calculated.

Fig. 6 shows the electrical circuit equivalent to Fig. 7 , where bus 1 is represented as a voltage source $V_{S}=1 \angle 0^{\circ}$ p.u., the load on bus 2 as an impedance $Z_{C}=V_{2} / I_{C}$ and the generator on bus 2 as a current source $\mathrm{I}_{\mathrm{G}}=\mathrm{S}_{\mathrm{G}} * / \mathrm{V}_{2} *[13]$.

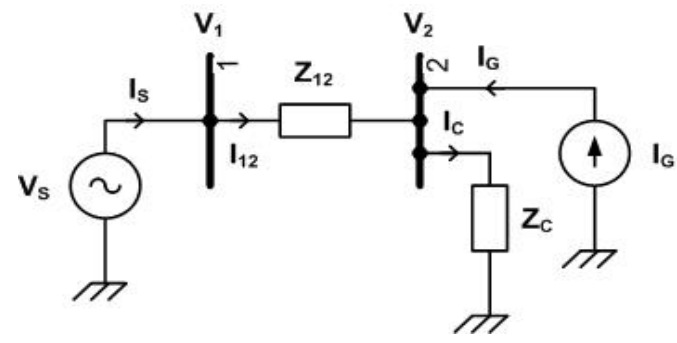

Fig. 7 Equivalent electric circuit for the two-busbar example system 
According to Kirchhoff's law of voltages:

$$
V_{2}=V_{1}-Z_{12} I_{12}
$$

Also, according to Kirchhoff's current law:

$$
I_{12}=I_{C}-I_{G}
$$

From $\mathbf{V}_{2}=\mathrm{V}_{\mathrm{x}}+\mathrm{j} \mathrm{V}_{\mathrm{y}}$, substituting (7) into (6) one obtains the voltage on bus 2 :

$$
V_{2}=0.974-j 0.014=0.974 \angle-0.8^{\circ}
$$

Therefore, the power supplied by the source is:

$$
S_{12}=V_{1} I_{12} *=1.0171+j 0.7343
$$

By applying the power summation method to the case study, we obtain the voltages and powers shown in Table II. It is observed that the voltage values in bus 2 and power supplied by the source are close to the calculated values.

TABLE II

Voltage ANd Powers ObTAINED WITH THE Power Summation Method

\begin{tabular}{ccccc}
\hline \hline Buses & $\begin{array}{c}\text { Voltage } \\
\text { (p.u.) }\end{array}$ & Angle $\left({ }^{\circ}\right)$ & $\begin{array}{c}\text { Pnet } \\
\text { (p.u.) }\end{array}$ & $\begin{array}{c}\text { Qnet } \\
\text { (p.u.) }\end{array}$ \\
\hline 1 & 1 & 0 & 0 & 0 \\
2 & 0.9740 & -0.8030 & 1 & 0.7 \\
$1-2$ & 0.0295 & 27.613 & 1.0164 & 0.7329 \\
\hline \hline
\end{tabular}

\section{CAse Study Modeling}

\section{A. Electrical System Based on IEEE Standard}

The distribution system under analysis is based on the IEEE 30-bus system (Fig. 8), with the following variations:

- The first six buses are considered (six busbar system);

- The interconnection between buses 2 and 4 is excluded (system with six branches);

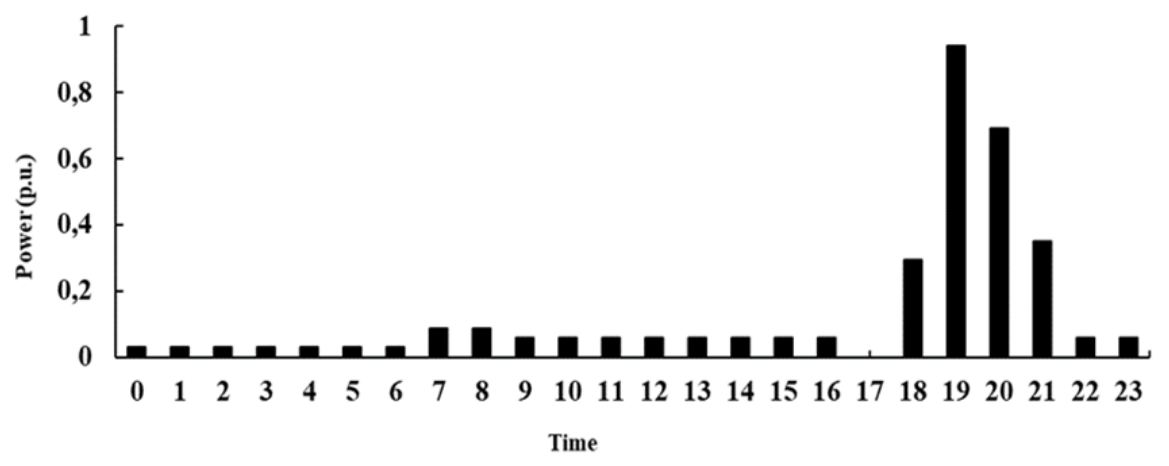

Fig. 9 Residential load profile

\section{C.Profile of Photovoltaic Generation and Energy Storage}

For the photovoltaic solar generation profile, solarimetric data of the Tanquinho Plant in Campinas-SP, Brazil corresponding to $03 / 01 / 2014$ were used. If the photovoltaic solar generator has mechanical and electrical tracker systems, the generation profile will be similar to the irradiation curve, and the active power injected into the electric system will be
- $\quad$ The distributed generator is connected to bus 5 instead of bus 2 ;

- The reactive power injected by the photovoltaic generator is considered null;

- An energy storage unit is also connected to bus 5 in order to improve voltage levels.

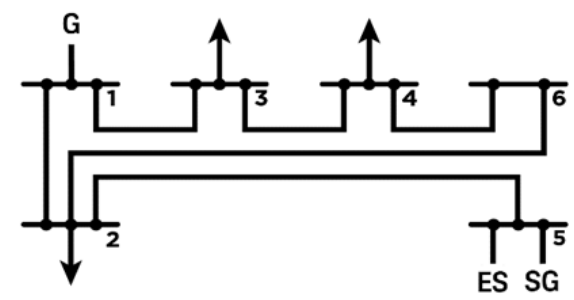

Fig. 8 Electrical system of six buses based on the IEEE standard of 30 buses $(\mathrm{G}-$ Generation, ES- Energy storage and SG - Solar generation)

\section{B. Load Profile}

The consumption profile for loads of the studied electrical system is constructed from data of a usual residence in Brazil. On the other hand, the production profile for the generator of the electric system is elaborated from data of solar irradiation in a locality of Brazil. A total of 24 power-flow simulations (for each hour of a typical day) are performed using the power summation method, and the behavior of the voltages in the system buses is analyzed.

Typical consumption values were used to construct the hourly load profile, where the maximum value of $3207.5 \mathrm{~W}$ was considered proportional to each of the nominal active and reactive powers of the IEEE-based electrical system loads, as shown in Fig. 9 for the active power consumed in bus $5\left(\mathrm{P}_{\mathrm{C} 5}=\right.$ 0.942 p.u.). It is observed that the peak of energy consumption is between $6 \mathrm{pm}$ and $9 \mathrm{pm}$ (maximum value around $7 \mathrm{pm}$ ), and there is considerable consumption between $7 \mathrm{~h}$ and $8 \mathrm{~h}$. approximately proportional to this curve. Therefore, the photovoltaic generation profile per hour with a nominal value of 0.4 p.u. is shown in Fig. 10, while the reactive power injected by the solar generator is zero. Note that the maximum generation is around midday and that there are generation drops at $8 \mathrm{~h}$ and $16 \mathrm{~h}$ as a result of a cloudy or rainy day. 


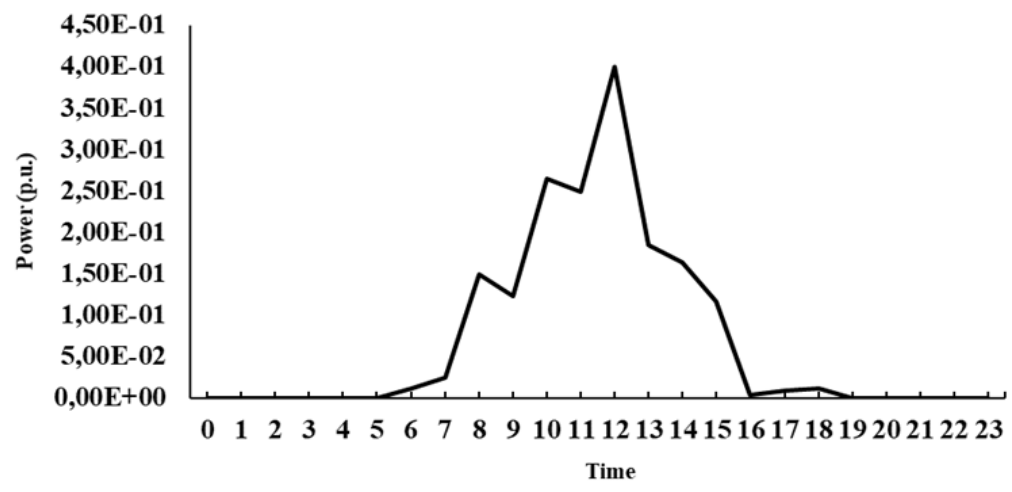

Fig. 10 Active power injected by the photovoltaic generator, based on measured solar irradiation

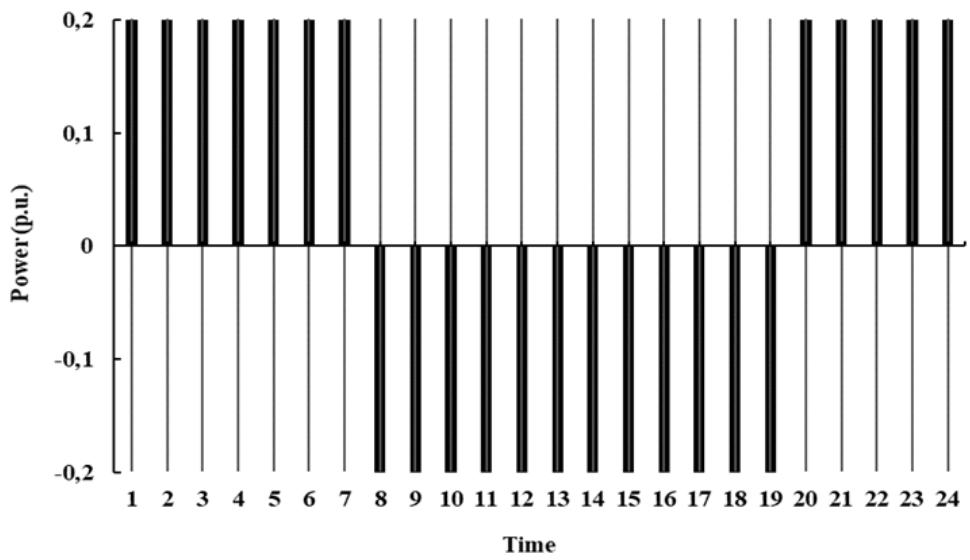

Fig. 11 Profile of loading and unloading of energy storage

The addition of a solar photovoltaic generator causes elevation of the voltage level around midday hours, at the bus in which it is connected. Besides that, typical load profiles require more generation at night hours. Therefore, an energy storage system can be utilized to consume the excess of energy production in the morning and help supplying heavy loads at night, so it works as a power compensator.

Power profile of the energy storage unit depends on the designer criterion. Fig. 11 shows a simple power profile that considers storing energy at a constant rate when the solar photovoltaic unit is generating, and supply energy when there is no available solar energy. It can be noticed that the positive area has to be approximately equal to the negative area in the $\mathrm{P}_{\mathrm{A}}$ vs $\mathrm{t}$ curve. In this work, a nominal power $\left(\mathrm{P}_{\mathrm{A}}= \pm 0.2\right.$ p.u. $)$ slightly lower than the generator power was selected.

\section{V.ANALYSIS AND DISCUSSION}

A. Case Study 1: Distribution System with Loads and Solar Generator

The summation of powers method is used to calculate the modules and angles of the voltages in the buses of the electrical system under analysis. Figs. 12 and 13 show the behavior of the voltage and angles modules in the system buses for the load and generation profiles considered in the work. In which it is observed that bus 5 when it is in the moment of peak consumption does not meet the recommendations of the standard. The high active and reactive power consumption around $7 \mathrm{pm}$ causes the voltage drop in bus 5 with a value of 0.8084 p.u. (as can be seen in Table III where the voltage results for this particular time are). But the other voltages remain within the recommended values. Considerable photovoltaic generation around the $12 \mathrm{~h}$ produces a small voltage rise in the bus 5 , still within the permitted values for the appropriate voltage level (less than 1.05 p.u.). 


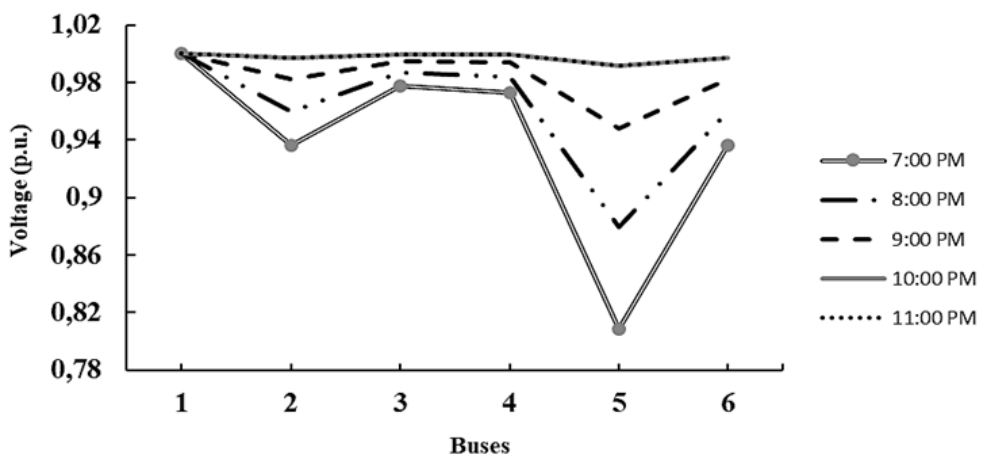

Fig. 12 Voltage profile on bus 5 for a typical day

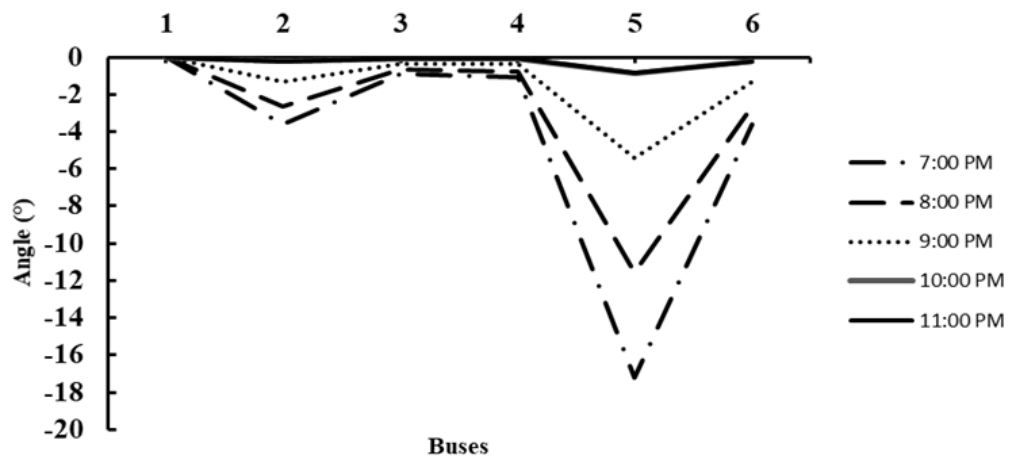

Fig. 13 Angle profile on bus 5 for a typical day

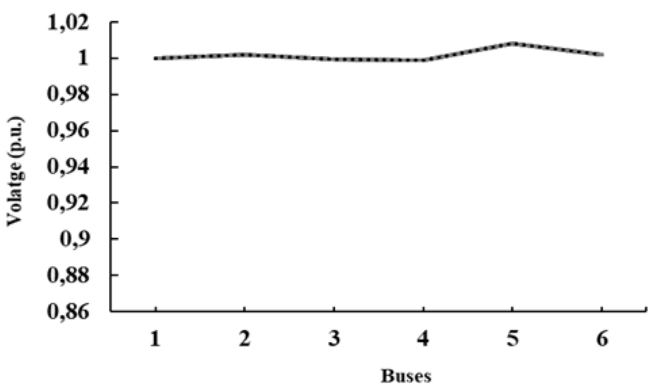

Fig. 14 Voltage profile on bus 5 with generator and storage unit

TABLE III

Bus TENSION LEVELS 5 TO 7 PM WITHOUT STORAGE UNIT

\begin{tabular}{cc}
\hline \hline Buses & Voltage (p.u.) \\
\hline 1 & 1 \\
2 & 0.9362 \\
3 & 0.9775 \\
4 & 0.9729 \\
5 & 0.8084 \\
6 & 0.9362 \\
\hline \hline
\end{tabular}

B.Distribution System with Loads, Solar Generator and Energy Storage

Simulation results are presented in Figs. 14 and 15, for the voltage levels and angles on bus 5 when connecting an energy storage unit to the distribution system with solar generator and loads. It can be noticed that the voltages on bus 5 are all in adequate values (Table IV), even at the time when the load consumption is high and the solar power generation is maximum. Other design criterion for the power profile implies calculating it from grid power consumption, so it can supply almost constant power all day.

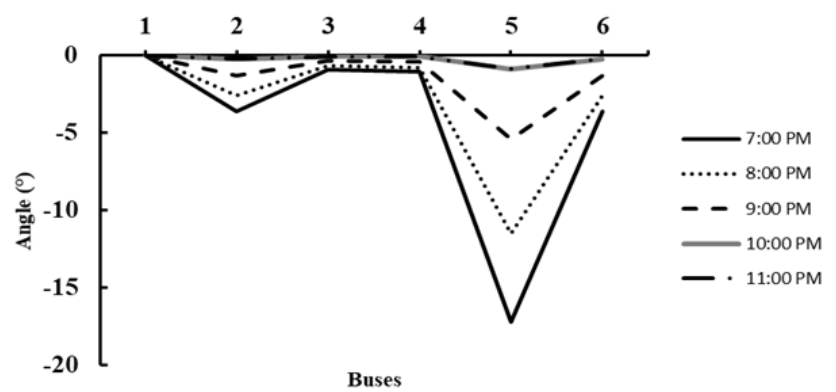

Fig. 15 Angle profile on bus 5 with generator and storage unit

TABLE IV BUS TENSION LEVELS 5 TO 7 PM WITH STORAGE UNIT

\begin{tabular}{cc}
\hline \hline Buses & Voltage (p.u.) \\
\hline 1 & 1 \\
2 & 1.0022 \\
3 & 0.9993 \\
4 & 0.9991 \\
5 & 1.0084 \\
6 & 1.0022 \\
\hline \hline
\end{tabular}

\section{CONCLUSION}

Load flow simulations were performed for each hour of the day in an electrical system based on the IEEE standard, considering a consumption profile of a common residence and a generation profile corresponding to the solar irradiation in a 
locality. The results show that the solar photovoltaic generator produces a slight rise in voltage around noon on the bus it is connected to, and that the demand for peak power at night is not offset by the solar generator.

It was demonstrated that an energy storage unit can compensate the power consumption of a distributed system with residential loads and solar generator, so the voltage levels on the buses of the electrical system are categorized as adequate according to national standard.

Future work involves investigating more power profiles of the energy storage unit, addition of diesel generators and analysis in transient state.

\section{ACKNOWLEDGMENT}

This work was supported by the agencies CNPq, CAPES and FAPESP (2016/08645-9), ANEEL (CPFL-PA3032) and BYD ENERGY through the PADIS program.

\section{REFERENCES}

[1] Lima, Diana R. U. Desenvolvimento de Modelos de Redes de Baixa Tensão para Estudos de Fluxo de Potência. Universidade de São Paulo. São Carlos, 2015.

[2] Afifi, Sara N. Impact of Hybrid Distributed Generation Allocation on Short Circuit Currents in Distribution Systems. Brunel University London-Brunel Institute of Power Systems. London, 2017.

[3] Manditereza, P. T. e Bansal, R. "Renewable distributed generation: The hidden challenges - A review from the protection perspective," Renewable and Sustainable Energy Reviews, vol. 58, pp. 1457-1465, 5, 2016 .

[4] Walling, R. A. et al. "Summary of Distributed Resources Impact on Power Delivery Systems," IEEE Transactions on Power Delivery, vol. 23, pp. 1636-1644, 2008.

[5] Lopes, J. A. P. et al. "Integrating distributed generation into electric power systems: A review of drivers, challenges and opportunities," Electr. Power Syst. Res., vol. 77, pp. 1189-1203, 7, 2007.

[6] Kaur, G. e Vaziri, M. Y. "Effects of distributed generation (DG) interconnections on protection of distribution feeders," in 2006 IEEE Power Engineering Society General Meeting, 2006, pp. 8 pp.

[7] Monticelli, A. (1983). Fluxo de Carga em Redes de Energia Elétrica. Edgar Blucher, Rio de Janeiro - RJ.

[8] Sarabia, A. F. Impact of distributed generation on distribution system. Aalborg University. Denmark, 2011.

[9] Procedimentos de Distribuição de Energia Elétrica no Sistema Elétrico Nacional (PRODIST) - Módulo 8 - Qualidade da Energia Elétrica Revisão 6, ANEEL, 76pp., 2014.

[10] Kersting, W. H. (1991). Radial Distribution Test Feeders, IEEE Trans. Power Systems, vol. 6, pp. 975-985.

[11] C. G. Renato (1990). New Method for the Analysis of Distribution Networks, IEEE Trans. Power Delivery, vol. 5, pp. 391-396.

[12] Das, D.; Nagi, H. S. and Kothari, D. P. (1994) Novel Method for Solving Radial Distribution Networks, in IEEE Gener. Transm. Distrib. pp. 291-298.

[13] Souza, B. A.; H. D. M. Braz; Albuquerque, J. M. C.; Gutterres, J. G. G. (2006). Fluxo de Carga em Sistemas de Distribuição Radiais com Geração Distribuída: Método da Soma de Potência Modificado. IEEE Latin America Transactions, vol. 4, no. 3. 